\title{
Molecular divergence of the serotype-specific plasmid (pSLT) among strains of Salmonella typhimurium of human and veterinary origin and comparison of pSLT with the serotype specific plasmids of $S$. enteritidis and S. dublin
}

\author{
D. J.PLATT, J.TAGGART and K. A. HERAGHTY* \\ University Department of Bacteriology, Royal Infirmary, Castle Street, Glasgow G4 OSF and Department of \\ Microbiology, Royal Hospital for Sick Children, Yorkhill, Glasgow
}

\begin{abstract}
Summary. Molecular variants of the serotype-specific plasmid (SSP) of Salmonella typhimurium (pSLT) were recognised in clinical and veterinary isolates by restriction enzyme fingerprinting. Three had undergone minor DNA rearrangements, whereas two had acquired resistance determinants to a wide range of antimicrobial agents including gentamicin, trimethoprim, tetracycline, streptomycin, ampicillin ( $\mathrm{Ap}$ ) and kanamycin $(\mathrm{Km})$. One of the latter was the result of co-integrate formation with an IncX, conjugative $\mathrm{R}$-plasmid that specified ApKm resistance. The co-integrate plasmid (pOG669) was incompatible with, and displaced, pSLT and its molecular variants. The restriction fingerprints of SSPs of $S$. enteritidis and $S$. dublin were compared with pSLT. All were related at the $35 \%$ level on the basis of a Dice coefficient of similarity. The SSPs of $S$. enteritidis and $S$. dublin were incompatible with the co-integrate plasmid pOG669. Whereas in $S$. enteritidis this resulted from incompatibility with the pSLT component (the SSP was compatible with the IncX component), the converse was found with $S$. dublin.
\end{abstract}

\section{Introduction}

Several independent studies have shown that certain serotypes of Salmonella harbour serotypespecific plasmids (SSPs) (Helmuth et al., 1985). The most notable serotypes were $S$. typhimurium (Jones et al., 1982), S. enteritidis (Nakamura et al., 1985) and $S$. dublin (Terakado et al., 1983). Popoff et al. (1984) demonstrated a high level of molecular relatedness between the SSPs of $S$. typhimurium and $S$. dublin by hybridisation and Baird et al. (1985) showed extensive homology between the regions of these plasmids associated with virulence.

The SSPs of salmonellae have not been assigned to an established incompatibility group (Inc). The plasmids MP10 (probably synonymous with pSLT) and $A^{*}$ were studied by Anderson and Smith (1972) who demonstrated their compatibility with $\mathrm{IncF}$, $F_{\mathrm{I}}$ and $\mathrm{H}_{\mathrm{I}}$. They were not compatible with $\mathrm{F}_{\mathrm{I}}$ me plasmids. Willshaw et al. (1978), on the basis of DNA reassociation studies, concluded that their

Received 11 Jan. 1988; revised version accepted 6 June 1988 incompatibility did not reflect a close phylogenetic relationship.

The SSP of S. typhimurium was designated pSLT by Jones et al. (1982), who used S. typhimurium LT2 as their reference strain. In an earlier report (Brown et al., 1986) we showed that this plasmid was readily recognised by restriction enzyme fingerprinting with Pst 1 and Smal and was present among most, but not all, of the phage types of $S$. typhimurium examined. Detailed comparison of the fingerprints from clinical isolates with that of pSLT was restricted to those isolates that harboured a single plasmid and thus could be interpreted unequivocally. In each of 15 cases the plasmid was identical with pSLT on the basis of Pstl and Smal fingerprints and we concluded that the SSP of $S$. typhimurium was remarkably conserved.

In this study we have extended previous investigations, examined a wider range of bacterial strains, and further defined the interpretation of fingerprint data to demonstrate molecular divergence of the SSP of $S$. typhimurium. The restriction fingerprints 
of SSPs from $S$. typhimurium, $S$. enteritidis and $S$. dublin have also been compared with each other together with certain of their incompatibility properties.

\section{Materials and methods}

\section{Bacterial strains and plasmids}

Clinical isolates of $S$. typhimurium, $S$. enteritidis and $S$. dublin were from the departmental collection which came from various laboratories throughout Scotland including the Microbiology Department, Royal Hospital for Sick Children, Glasgow (RHSC); Veterinary Investigation Centre, West of Scotland Agricultural College, Auchincruive; and the Scottish Salmonella Reference Laboratory (SSRL), Stobhill Hospital, Glasgow. SSRL had confirmed the serotype and phage type of the $S$. typhimurium isolates.

$S$. typhimurium LT2 (Zinder and Lederberg, 1952) ATCC 235564 was used as a source of the plasmid pSLT. In view of its early isolation, ready availability and widespread usage, this plasmid was chosen to provide reference restriction enzyme fingerprints. However, it was also compared with the indigenous plasmid (designated pOG660) of $S$. typhimurium NCTC 73 which was isolated in 1917 and antedates LT2. E. coli K12 J53-2 and J62-1 were used as recipient strains for plasmid transfer from S. typhimurium (Platt et al., 1984). E. coli K 12 J62:: Tn7 was kindly provided by Dr Hilary Richards as a chromosomal source of the transposon Tn7. The IncX plasmid, Tp231, was obtained from the National Collection of Type Cultures and used to confirm the Inc group of pOG670 and the dual incompatibility properties of pOG669. Bacterial strains are shown in table I.

\section{Construction of plasmid pOG664}

Plasmid pOG670 was transferred from $S$. typhimurium GRI31486 to a lac ${ }^{-}$strain of E. coli $\mathrm{K} 12$ that encoded a chromosomal copy of $\operatorname{Tn} 7(\mathrm{~J} 62:: \operatorname{Tn} 7)$. Further conjugation to a rifampicin resistant $\mathrm{lac}^{+} E$. coli (J53-2) with trimethoprim and rifampicin selection allowed the isolation of the plasmid pOG670::Tn7 which was designated pOG664 and used to test the dual incompatibility of pOG669.

\section{Construction of co-integrate plasmid pOG665}

Plasmid pOG670 was transferred from $S$. typhimurium GRI31486 to an E. coli K12 auxotroph, and then by further conjugation to $S$. typhimurium LT2, by use of minimal medium and ampicillin selection; this strain was designated LT2-4. S. typhimurium LT2-4 was successively subcultured six times on CLED agar at $40^{\circ} \mathrm{C}$ with ampicillin (Ap) and kanamycin $(\mathrm{Km})$ selection. Single colonies were examined for the presence of a co-integrate plasmid (pOG665) by agarose gel electrophoresis, as described below.

\section{Plasmid profiles and restriction fingerprints}

Plasmid DNA was examined in crude lysates by a modification of the method of Platt and Sommerville (1981). The equivalent of 12-20 colonies of an overnight

Table I. Bacterial strains and plasmids

\begin{tabular}{|c|c|c|c|c|}
\hline Species and designation & $\begin{array}{l}\text { Phage type } \\
\text { (DT) }\end{array}$ & $\begin{array}{l}\text { Plasmid profile } \\
\text { (mol. wt in kb) }\end{array}$ & Plasmid designation & $\begin{array}{l}\text { Source or } \\
\text { reference }\end{array}$ \\
\hline \multicolumn{5}{|l|}{ S. typhimurium } \\
\hline NCTC 73 & 9 & 87 & pOG660† & Isolated in 1917 \\
\hline LT2 & 4 & 87 & pSLT & \multirow{4}{*}{$\begin{array}{l}\text { Brown, Munro and Platt, } 1986 \\
\text { This paper }\end{array}$} \\
\hline LT2-4 & NT & 87,52 & pSLT, pOG670 ) & \\
\hline LT2-5 & NT & 139 & pOG665 & \\
\hline GRI 37286 & 12 & 87 & pOG666 & \\
\hline GRI 37386 & 12 & 87 & pOG 667 & \multirow{3}{*}{$\begin{array}{l}\text { Human strains from RHSC iso- } \\
\text { lated between } 1977 \text { and } 1984\end{array}$} \\
\hline GRI 37486 & RDNC & 87 & pOG668 & \\
\hline GRI 37586 & $204 C$ & $87^{*}, 52,4 \cdot 3$ & pOG $666^{*}$ & \\
\hline GRI 37686 & $204 C$ & $87^{*}, 52,4 \cdot 3$ & pOG $666^{*}$ & \multirow{4}{*}{ Bovine strains isolated in 1985} \\
\hline GRI 30986 & $204 \mathrm{C}$ & $174,139^{*}, 87$ & pOG669 & \\
\hline GRI 31486 & $204 C$ & $174,87,52^{*}, 7.2$ & pOG670* & \\
\hline GRI 31986 & $204 C$ & $101^{*}, 4 \cdot 3$ & pOG $672^{*}$ & \\
\hline \multicolumn{5}{|l|}{ S. enteritidis } \\
\hline GRI 16485 & NT & 52 & pOG674 & \multirow{3}{*}{ Human strains isolated in 1985} \\
\hline S.dublin & & & & \\
\hline GRI 34285 & NT & 72 & pOG675 & \\
\hline
\end{tabular}

NT $=$ not tested.

* Indicates the approximate mol. wt of the designated plasmid in strains that harboured more than one plasmid.

$\dagger$ Indistinguishable from pSLT on the basis of PstI, SmaI and AvaII fingerprints 
culture on Nutrient Agar (Oxoid, CM3) was suspended in $300 \mu \mathrm{l}$ of electrophoresis buffer (EB) $(89 \mathrm{mM}$ Tris, $89 \mathrm{~mm}$ boric acid, $1.25 \mathrm{~mm}$ EDTA, pH 8.2) in $1.5-\mathrm{ml}$ Eppendorf tubes; $200 \mu \mathrm{l}$ of sodium dodecyl sulphate (SDS) $10 \% \mathrm{w} / \mathrm{v}$ in EB were added and the tubes were mixed gently by inversion. After being heated at $50^{\circ} \mathrm{C}$ for $5 \mathrm{~min}$, the crude lysates were centrifuged for $15 \mathrm{~min}$ $(9980 \mathrm{~g})$ in a micro-centrifuge. The supernatant fraction $(100 \mu \mathrm{l})$ was loaded on to a vertical agarose gel $(0.7 \%$, Sigma, type II) together with $5 \mu$ l of tracking dye (sucrose $25 \%, 8 \mathrm{~mm}$ sodium acetate, $3.5 \mathrm{~mm}$, SDS, $0.7 \mathrm{~mm}$ bromophenol blue). Electrophoresis was carried out for $1 \mathrm{~h}$ at $100 \mathrm{~V}$ followed by $4 \mathrm{~h}$ at $200 \mathrm{~V}$ (constant voltage). Gels were stained with ethidium bromide $6 \mu \mathrm{g} / \mathrm{ml}$ for $15 \mathrm{~min}$, viewed with a UV transilluminator $(365 \mathrm{~nm})$ and photographed on type 665 film (Polaroid). The mol. wts of plasmids were determined by reference to plasmids of known mol. wt; Rts 1 (174 kb), RA-1 (123 kb), R1 $(90 \mathrm{~kb}), \mathrm{R} 702(67 \mathrm{~kb})$ and RP4 (52 kb). Supercoiled ladder (Gibco-BRL, Paisley) was used for the mol.-wt estimation of small plasmids $(<15 \mathrm{~kb})$. Mol.-wt values incorporated into plasmid profiles were determined on a minimum of two occasions.

Restriction fingerprinting was performed as previously described in detail (Platt et al., 1986). Plasmid DNA from clinical isolates and transconjugants was extracted and purified by a modification of the method of Birnboim and Doly (1979). Restriction enzymes were obtained from Gibco-BRL except Bsp1286 (CP Laboratories, Bishops Stortford, Herts) and used according to the manufacturer's instructions. Restriction fingerprints were compared by using a coefficient of similarity (Dice, 1945) calculated from the formula $S_{D}(\%)=$ $[2 \mathrm{~m} /(\mathrm{a}+\mathrm{b})] \times 100$, where ' $\mathrm{m}$ ' was the number of restriction fragments common to two plasmids ( $\mathrm{A}$ and $\mathrm{B})$, and ' $a$ ' and ' $b$ ' were the total numbers of fragments generated from each plasmid after digestion by the same restriction enzyme.

\section{Interpretation of restriction fingerprints}

The following general rules were applied to the interpretation of plasmid fingerprints:

(1) To establish that an observed fingerprint represented a variant of PSLT demanded that its recognition was initially in a strain of $S$. typhimurium in which it was the sole plasmid or was similarly present in an E. coli transconjugant. In the latter situation each of the fragments detected must have been present in the original isolate of $S$. typhimurium.

(2) If the difference between the observed variant fingerprint and pSLT was solely due to an additional fragment or fragments the same result must have been obtained when the plasmid was digested with twice the standard amount of restriction enzyme to exclude the presence of the products of partial digestion.

(3) Subsequent presumptive recognition of variants in clinical or veterinary isolates that contained additional plasmids was accepted if the additional plasmid was substantially different in copy number (Platt and Taggart, 1987) or if the variant had lost at least one fragment.

\section{Incompatibility properties determined on the basis of interaction with plasmid pOG669}

Dual incompatibility properties of the naturally occurring co-integrate plasmid, pOG669 (Platt, 1987), were confirmed on the basis of interactions with Tp231 (IncX), pOG664 and pOG672, a resistant derivative of pSLT (table II). Plasmid pOG669 was used to investigate the

Table II. Summary of characteristics of the plasmids studied

\begin{tabular}{|c|c|c|c|c|c|}
\hline \multirow[b]{2}{*}{ Plasmid } & \multirow{2}{*}{$\begin{array}{c}\text { Transferability to } \\
\text { E. coli } \mathrm{K} 12\end{array}$} & \multirow{2}{*}{$\begin{array}{c}\text { Resistance } \\
\text { determinants }\end{array}$} & \multicolumn{2}{|c|}{ Incompatibility with } & \multirow[b]{2}{*}{ Origin } \\
\hline & & & pOG669 & pOG670 & \\
\hline pOG664 & + & Ap Km Tp & + & NT & pOG670::Tn7 \\
\hline pOG 665 & + & $\mathrm{Ap} \mathrm{Km}$ & NT & NT & pOG670/p SLT co-integrate \\
\hline pOG666 & - & - & + & - & \\
\hline pOG667 & - & 一 & + & - & naturally occurring variants of pSLT \\
\hline pOG668 & - & 一 & + & $-\int$ & \\
\hline pOG669 & + & Ap Km & NT & NT & \\
\hline pOG 670 & + & Ap Km & NT & NT & IncX R-plasmid \\
\hline pOG672 & + & Tc Sm Gm Tob Tp & + & - & naturally occurring variant of pSLT \\
\hline pOG673 & + & Tc Sm Gm Tob Tp & + & - & conjugational rearrangement of pOG672 \\
\hline pOG674 & - & - & + & - & SSP S. enteritidis \\
\hline pOG675 & - & - & + & + & SSP $S$. dublin \\
\hline pSLT & - & - & + & - & SSP $S$. typhimurium LT2 \\
\hline Tp231 & + & $\mathrm{Ap} \mathrm{Tc} \mathrm{Cm}$ & + & + & IncX reference plasmid \\
\hline
\end{tabular}

Ap, ampicillin; Km, kanamycin; Tp, trimethoprim; Tc, tetracycline; Sm, streptomycin; Gm, gentamicin; Tob, tobramycin. NT $=$ not tested. 
incompatibility properties of plasmids related to pSLT and the SSPs of $S$. enteritidis and $S$. dublin as follows: pOG669 was introduced into a strain of each serotype by conjugation, and selected for by $\mathrm{Ap}$ or $\mathrm{Km}$ resistance; the presence of both plasmids in transconjugants was confirmed by agarose gel electrophoresis. After unselected growth, segregation was detected by disk-diffusion sensitivity testing. ApKm-resistant clones remained stable with respect to these determinants and harboured only the 139-kb plasmid whereas a SmaI fingerprint of ApKm sensitive clones confirmed the presence of only the resident plasmid.

Plasmid pOG670 (the IncX, ApKm conjugative Rplasmid component of pOG669) was investigated in parallel to establish whether any incompatibility observed was a consequence of the pSLT component of the cointegrate.

\section{Mobilisation of plasmid pOG672}

The RP1 derivative plasmid pMR5 is temperaturesensitive for replication (Robinson et al., 1980). It was transferred into $E$. coli $\mathrm{K} 12 \mathrm{~J} 53-2$, which already contained plasmid pOG672, by conjugation and was selected for with rifampicin and kanamycin. This strain was used to transfer pOG672 into $S$. dublin GRI 34285 which already contained plasmid pOG675, minimal medium being used to counterselect against the plasmid donor and trimethoprim resistance to select for incoming pOG672. Transconjugants were grown at $37^{\circ} \mathrm{C}$ to effect the elimination of pMR5, which was confirmed by loss of ApKm resistance. Agarose gel electrophoresis was used to confirm that pOG675 and pOG672 were present in S. dublin.

\section{Results}

\section{Occurrence of serotype-specific plasmids}

Seven isolates of $S$. typhimurium from human or veterinary sources harboured plasmids which gave PstI or SmaI fingerprints, or both, related to but different from that obtained with the serotypespecific plasmid (pSLT) of $S$. typhimurium LT2. A plasmid indistinguishable from pSLT was demonstrated in $S$. typhimurium NCTC 73. The characteristics of the isolates are shown in table I and the plasmids in table II. Plasmids pOG666, 667 and 668 were all detected in human isolates which harboured a single plasmid. PstI and SmaI fingerprints are shown in fig. 1 , together with pSLT; pOG666 differed from pSLT only in the SmaI fingerprint, pOG668 only in the PstI fingerprint and pOG667 in both PstI and SmaI fingerprints. Whereas pOG666 was first recognised in a strain of S. typhimurium that belonged to phage type (DT)12, it was also presumptively identified in two isolates of DT $204 c$ which harboured additional plasmids.

\section{$a b c d e f g h i j k$ I $m$ opq}

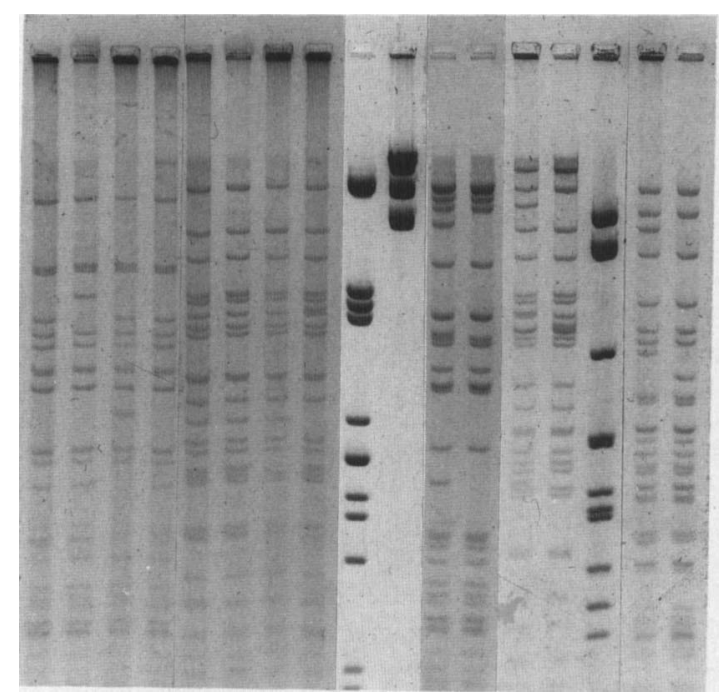

Fig. 1. Tracks a-d and e-h: PstI and SmaI digests, respectively; of pSLT, pOG668, pOG667 and pOG666. Tracks i, j, o: Pst I, Smal and AvaII digests of bacteriophage $\lambda$. Tracks k, l, m, n, p, q: pOG672 and pOG673 digested with PstI, SmaI and AvaII respectively. Fragments shown range from $1 \mathrm{~kb}$ to $19 \mathrm{~kb}$.

Plasmid pOG669 was first recognised during the investigation of an outbreak of salmonellosis among cattle. S. typhimurium GRI 30986 harboured three plasmids (Plasmid profiles 120, 96, 60). Pst I and SmaI fingerprints of the original isolate indicated that pSLT was present. After R-transfer the analysis of transconjugants indicated that the $87-\mathrm{kb}$ plasmid specified resistance to streptomycin, gentamicin and tobramycin and bore no resemblance to pSLT in PstI and SmaI fingerprints. However, fingerprints of the $139-\mathrm{kb}$ plasmid that specified ampicillin and kanamycin resistance contained all the restriction fragments of pSLT together with several additional fragments. Furthermore, a $52-\mathrm{kb}$ IncX plasmid (pOG670) that specified ApKm resistance had been demonstrated in other $S$. typhimurium isolates from the same outbreak, the restriction fragments of which corresponded to the additional fragments found in pOG669. These results strongly suggested that the formation of pOG669 was the result of co-integration between pSLT and pOG670. This was confirmed by the construction of pOG665 in vitro. The restriction fingerprints of pOG669 and pOG665 were very similar but not identical and indicated that the co-integration site was different in the natural co-integrate and that constructed in vitro.

Fig. 2 shows PstI, SmaI and AvaII fingerprints of the co-integrate plasmid pOG669 together with 


\section{$a b c d e f g h i j k l$}

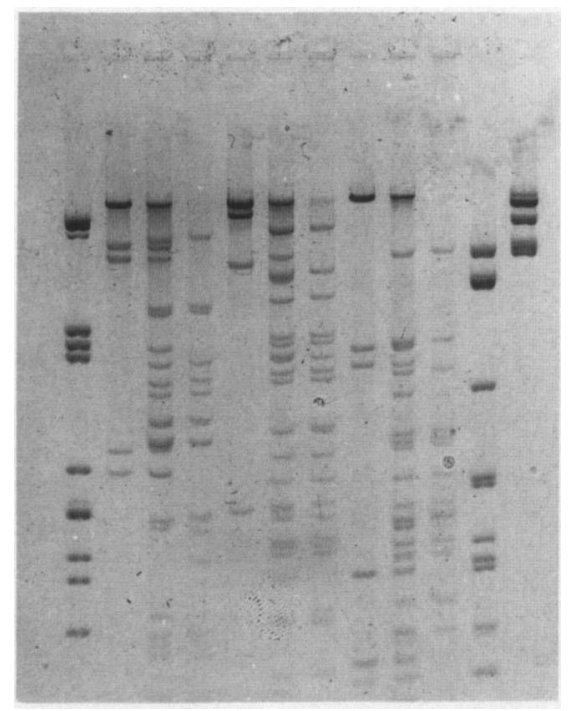

Fig. 2. Tracks a, k, l: bacteriophage $\lambda$ digested with PstI, AvaII and $S m a I$ respectively. Tracks b, e, h show pOG670, tracks c, f, i show pOG669, and tracks d, g, j show pSLT digested with $P$ st I (b, c, d), SmaI (e, f, g) and $\operatorname{AvaII}(\mathrm{h}, \mathrm{i}, \mathrm{j})$.

those of pOG670 and SLT from which it was derived.

\section{Plasmids pOG672 and pOG673}

When conjugative R-transfer was performed from S. typhimurium GRI 31986 (table I), transconjugants were obtained in $E$. coli $\mathrm{K} 12$ from both tetracycline and streptomycin selection plates. Each harboured a single plasmid of about $101 \mathrm{~kb}$, although a new plasmid (pOG673) was consistently smaller than pOG672. Each specified the same resistance determinants including gentamicin (table II) and although the restriction fingerprints were very similar, differences were detected. Fig. 1 shows PstI, SmaI and AvaII fingerprints of both pOG672 and pOG673. With each enzyme, restriction fragments present in the fingerprints of pOG672 were absent from those of pOG673. Whereas all the restriction fragments of pOG672 in $E$. coli $\mathrm{K} 12$ matched fragments in a digest of $S$. typhimurium GRI 31986, pOG673 lacked fragments present in both. Thus, pOG672 was the 'wild type' plasmid and pOG673 a deletion derivative of it obtained during conjugation with $E$. coli K 12 .

The PstI, SmaI and AvaII fingerprints of variant plasmids were compared quantitatively with that of pSLT by use of the Dice coefficient $\left(S_{D}\right)$ of similarity. Three of the variants (pOG666, 667 and 668 ) have diverged minimally from pSLT and had $\mathrm{S}_{\mathrm{D}}$ values $>90 \%$. Plasmids pOG672 and pOG673 produced lower $\mathrm{S}_{\mathrm{D}}$ values $(76 \%$ and $75 \%$ respectively) which reflect the increase in the mol. wt of these plasmids. The $S_{D}$ values obtained when pOG669 was compared with pSLT were similar (mean $77 \%$ for the three enzymes), despite a larger increase in the mol. wt. Although pOG670 contributed significantly to the total mol. wt of the cointegrate, the $S_{D}$ value was higher than might have been expected. This was because pOG670 contributed fewer restriction fragments, in proportion to its mol. wt, than did pSLT.

\section{Incompatibility studies with plasmid pOG669}

Plasmid pOG669 was incompatible with both Tp231, a reference IncX plasmid, and pOG672 a naturally occurring resistant derivative of pSLT. In each case selection for the incoming plasmid ( $T$ p231 and pOG672) resulted in the isolation of transconjugants that harboured both plasmids. Subsequent growth in the absence of selection pressure for either plasmid resulted in bi-directional segregation; pOG669 was the more stable in both plasmid combinations. However, when pOG664 was introduced into a strain that harboured pOG669, no transconjugants harboured both plasmids; pOG669 was consistently displaced by pOG664.

When pOG669 was introduced into S. typhimurium LT2 or strains that harboured one of the variant plasmids described above, the plasmids were incompatible (table II). Similar results were obtained with $S$. enteritidis and $S$. dublin. However, to exclude the possibility that incompatibility was the result of interaction between the IncX component of the co-integrate and the resident plasmid, pOG670 was introduced separately into each strain. With the exception of $S$. dublin, pOG670 was compatible with each of the resident plasmids. The SSP of $S$. dublin (pOG675) therefore exhibited incompatibility with both pOG669 and pOG670. To distinguish between dual incompatibility and IncX properties alone, pOG672 was mobilised into $S$. dublin by pMR5 which was subsequently eliminated by growth at the non-permissive temperature; pOG675 was incompatible with pOG672 and indicated IncX incompatibility alone.

\section{Relationships between the SSPs of S. typhimurium, $S$. enteritidis and $S$. dublin on the basis of quantitative comparison of restriction fingerprints}

Visual inspection of the fingerprints obtained after digestion with Pst I and SmaI indicated little overall similarity. The fragmentation patterns were readily identified and distinguished. However 
Table III. Molecular relatedness of variants of the S. typhimurium SSP to plasmid pSLT from S. typhimurium LT2

\begin{tabular}{|c|c|c|c|c|c|c|c|c|c|}
\hline \multirow{2}{*}{$\begin{array}{l}\text { Restriction enzyme } \\
\text { used to obtain } \\
\text { fingerprint }\end{array}$} & \multicolumn{9}{|c|}{$\begin{array}{l}\text { Dice coefficient of similarity (\%) after comparison of } \\
\text { pSLT with molecular variants of the S. typhimurium SSP }\end{array}$} \\
\hline & pOG666 & pOG667 & pOG668 & pOG669 & & pOG670* & pOG672 & & pOG673 \\
\hline & & & & & S† & & & $\mathrm{S} \dagger$ & \\
\hline Pst I & 100 & 91 & 95 & 73 & 5 & 0 & 75 & 96 & 71 \\
\hline Sma I & 91 & 93 & 100 & 76 & 30 & 7 & 82 & 92 & 81 \\
\hline Ava II & & & & 82 & 47 & 9 & 71 & 95 & 73 \\
\hline
\end{tabular}

* Although not a molecular variant of pSLT this plasmid was included on the basis that together with pSLT it formed the cointegrate plasmid pOG669

S T The similarity coefficient obtained by comparing the plasmids on the left and right of the boxes.

quantitative comparison by use of $\mathrm{S}_{\mathrm{D}}$ values and by including two additional enzymes (AvaII and Bsp1286) showed that each of the plasmids was related at about the $35 \%$ level (table IV). These results indicate that the SSPs of $S$. enteritidis, $S$. dublin and $S$. typhimurium have all diverged to a similar extent and also that the relationship between the SSPs of $S$. enteritidis and $S$. dublin was no closer than each of them to $S$. typhimurium.

\section{Discussion}

Plasmid profile analysis has become established as an important tool in epidemiological investigations (Hawkey, 1987). Implicit in this application of plasmid detection is the diversification of plasmid profiles within and between outbreaks of infectious disease (Farrar, 1983). Recently, however, it has been recognised that some plasmids, notably those

Table IV. Molecular relatedness of SSPs from $S$. typhimurium, S. enteritidis and S. dublin on the basis of restriction fingerprints

\begin{tabular}{|c|c|c|c|c|c|}
\hline \multirow{2}{*}{$\begin{array}{l}\text { Serotypes from } \\
\text { which SSPs were } \\
\text { compared }\end{array}$} & \multicolumn{4}{|c|}{$\begin{array}{l}\text { Dice coefficient of similarity } \\
(\%) \text { for fingerprints obtained } \\
\text { with }\end{array}$} & \multirow{2}{*}{ Mean } \\
\hline & PstI & SmaI & AvaII & Bsp 1286 & \\
\hline \multicolumn{6}{|l|}{ S. typhimurium and } \\
\hline $\begin{array}{l}\text { S. enteritidis } \\
\text { S. typhimurium and }\end{array}$ & 21 & 38 & 46 & 39 & 36 \\
\hline S. dublin & 22 & 41 & 32 & 34 & 32 \\
\hline \multicolumn{6}{|l|}{ S. enteritidis and } \\
\hline S. dublin & 25 & 50 & 39 & 46 & 37.5 \\
\hline
\end{tabular}

associated with enhanced pathogenicity, are particularly stable and their demonstration confers negligible epidemiological specificity. These include the serotype-specific plasmids of salmonellae (Brown et al., 1986; Platt, 1987), R-plasmids of $S$. wein (Casalino et al., 1984) and several plasmids of Shigella sonnei (Prado et al., 1987). The results presented here demonstrate that various different molecular rearrangements have taken place in the SSP of $S$. typhimurium and these may restore a degree of epidemiological specificity. Molecular variants, which may include point mutations, were readily recognised in $P s t I$ or SmaI restriction enzyme fingerprints, or in both. This indicates that plasmid fingerprinting can resolve differences that remain undetected in plasmids profiles, and demonstrates that similarity of mol. wt is not a prerequisite of relatedness among SSPs of S. typhimurium. The recognition of molecular variants can be reconciled with our previous observation that PstI and SmaI fingerprints were highly conserved in a representative collection of 96 strains of $S$. typhimurium isolated during 1985 on the basis that the variant plasmids were detected among salmonellae that were isolated from either paediatric infections collected over a 7-year period or veterinary isolates associated with an outbreak during 1985.

Although the molecular mechanisms that gave rise to the pSLT variants pOG666, 667 and 668 are unknown, pOG669 is clearly the result of cointegration between pSLT and pOG670 (Platt, 1987, and this report). The behaviour of the latter plasmid supports some but not all of the proposals of Bennett et al. (1986); although it exhibits dual incompatibility properties, in the absence of selection pressure they are not unidirectional.

There are several clinical implications of the co- 
integration event. Firstly, the co-integrate plasmid is freely autotransmissible in vitro to a wide range of Salmonella serotypes, including those that lack SSPs. Secondly, when pOG669 was transferred to strains of $S$. typhimurium that harboured pSLT, the latter plasmid was displaced by incompatibility. Preliminary studies (Brown et al., unpublished data) have shown that strains that harboured either plasmid were equally pathogenic in mouse virulence tests, which suggests that co-integration has not diminished any virulence properties conferred by pSLT. Thirdly, the linkage of autotransmissibility, drug resistance and virulence properties may allow the dissemination of this plasmid among other organisms with an attendant increase in their pathogenic potential.

Restriction enzyme fingerprinting, in contrast to hybridisation, provides an indirect estimate of plasmid relatedness. Farrar (1983) has argued that if two plasmids generate identical restriction fragments, from two or more enzymes, they may be assumed to be identical plasmids; conversely, plasmids of the same size that produce entirely different fragmentation patterns are essentially unrelated plasmids; and, finally, plasmids of the same or different sizes may share homologous regions of DNA, which are detectable in restriction fingerprints. We have extended this argument to include a quantitative estimate of plasmid relatedness based on the Dice coefficient of similarity where the restriction enzymes are chosen to produce an optimal number of fragments (Platt et al., 1986).

In this study, such estimates were based on a minimum of 50 fragments (pOG666, 667 and 668) and substantially more where three or four enzymes were used (tables III and IV). Although useful, this approach is not without certain limitations and the results should be interpreted with caution. For example, when pOG669 and pOG672 were com-

\section{REFERENCES}

Anderson E S, Smith H R 1972 Fertility inhibition in strains of Salmonella typhimurium. Molecular and General Genetics 118, 79-84.

Baird G D, Manning E J, Jones P W 1985 Evidence for related virulence sequences in plasmids of Salmonella dublin and Salmonella typhimurium. Journal of General Microbiology 131 : 1815-1823

Bennett P M, Heritage J, Comanducci A, Dodd, H M 1986 Evolution of R-plasmids by replicon fusion. Journal of Antimicrobial Chemotherapy 18 Suppl C: 103-111.

Birnboim H C and Doly J 1979 A rapid alkaline extraction procedure for screening recombinant plasmid DNA. Nucleic Acids Research 7: 1513-1523.

Brown D J, Munro D S, Platt D J 1986 Recognition of the pared with pSLT the coefficients of similarity were 78 and $77 \%$ respectively (based on a mean of three enzymes) which suggested that each plasmid had diverged equally from pSLT. Although both plasmids contained additional DNA, pOG669 was about $36 \mathrm{~kb}$ larger than pOG672. Thus, when comparing plasmids, one of which contains a DNA insert, similarity coefficients are not only influenced by the size of the insert, but also by the number of restriction sites it possesses for the enzyme(s) used in their determination. Such problems do not occur when dealing with plasmids that differ only by deletions.

Popoff et al. (1984) concluded that the SSPs of salmonella, including $S$. typhimurium, $S$. enteritidis and $S$. dublin, represented a family of related plasmids on the basis of hybridisation studies and HindIII fingerprints. The data from PstI, SmaI, $A v a \mathrm{II}$ and $B s p 1286$ fingerprints are consistent with this conclusion. The incompatibility studies lend further support with respect to $S$. typhimurium and $S$. enteritidis but the findings with $S$. dublin were unexpected and not easily reconciled with either hybridisation (Popoff et al., 1984; Baird et al., 1985) or fingerprinting results. The role of these plasmids in virulence would lead to the conservation of those regions associated with virulence. If the SSP of $S$. dublin had undergone co-integration with an IncX plasmid at some stage in its history (analogous to the natural formation of pOG669), the maintenance of selection for virulence need not have co-selected for conservation of a pSLT incompatibility determinant; its subsequent deletion, extending into other regions, would then explain the reduced size, incompatibility and low level of fingerprint similarity compared with pSLT. Loss of this incompatibility determinant was observed among $F_{1}$ me plasmids (McConnell et al., 1979) and would support this hypothesis.

cryptic plasmid, pSLT by restriction fingerprinting and a study of its incidence in Scottish Salmonella isolates. Journal of Hygiene 97, 193-197.

Casalino M, Comanducci A, Nicoletti M, Maimone F 1984 Stability of plasmid content in Salmonella wein in late phases of epidemic history. Antimicrobial Agents and Chemotherapy 25 : 499-501.

Dice L R 1945 Measures of the amount of ecological association between species. Ecology 26: 297-302.

Farrar W E 1983 Molecular analysis of plasmids in epidemiologic investigation. Journal of Infectious Diseases 148: 1-6.

Hawkey P M 1987 Molecular methods for the investigation of bacterial cross-infection. Journal of Hospital Infection 9: 211-218.

Helmuth R, Stephan R, Bunge C, Hoog B, Steinbeck A, Bulling E 1985 Epidemiology of virulence-associated plasmids and 
outer membrane protein patterns within seven common Salmonella serotypes. Infection and Immunity 48: 175-182.

Jones G W, Rabert D K, Svinarich D M, Whitfield H J 1982 Association of adhesive, invasive and virulent phenotypes of Salmonella typhimurium with autonomous 60-megadalton plasmids. Infection and Immunity 38: 476-486.

McConnell M M, Smith H R, Leonardopoulos J, Anderson E S 1979 The value of plasmid studies in the epidemiology of infections due to drug-resistant Salmonella wein. Journal of Infectious Diseases 139: 178-190.

Nakamura M, Sato S, Ohya T, Suzuki S, Ikeda S 1985 Possible relationship of 36-megadalton Salmonella enteritidis plasmid to virulence in mice. Infection and Immunity 47: 831-833.

Platt D J 1987 Studies with Scottish salmonellae. Infections in Focus 1: 9-10.

Platt D J, Chesham J S, Brown D J, Kraft C A, Taggart J 1986 Restriction enzyme fingerprinting of enterobacterial plasmids: a simple strategy with wide application. Journal of Hygiene 97: 205-210.

Platt D J, Sommerville J S 1981 A simple method for the detection of resistance plasmids in Serratia species by transfer to members of the genus Enterobacter. Journal of Antimicrobial Chemotherapy 8: 145-152.

Platt D J, Sommerville J S, Gribben J 1984 Sequential acquisition of R-plasmids in vivo by Salmonella typhimurium. Journal of Antimicrobial Chemotherapy 13: 65-69.

Platt D J, Taggart J 1987 Molecular epidemiology: determination of plasmid sizes. Focus 9: 13.

Popoff M Y, Miras I, Coynault C, Lasselin C, Pardon P 1984 Molecular relationships between virulence plasmids of Salmonella serotypes typhimurium and dublin and large plasmids of other Salmonella serotypes. Annales de Microbiologie (Paris) 135: 389-398.

Prado D, Murray B E, Cleary T G, Pickering L K 1987 Limitations of using the plasmid pattern as an epidemiological tool for clinical isolates of Shigella sonnei. Journal of Infectious Diseases 155: 314-316.

Robinson M K, Bennett P M, Falkow S, Dodd H M 1980 Isolation of a temperature-sensitive derivative of RP1. Plasmid 3: 343-347.

Terakado N, Sekizaki T, Hashimoto K, Naitoh S 1983 Correlation between the presence of a fifty-megadalton plasmid in Salmonella dublin and virulence for mice. Infection and Immunity 41 : 443-444.

Willshaw G A, Smith H R, Anderson E S 1978 Molecular studies of $\mathrm{F}_{1}$ me resistance plasmids, particularly in epidemic Salmonella typhimurium. Molecular and General Genetics 159: 111-116.

Zinder N D, Lederberg J 1952 Genetic exchange in Salmonella. Journal of Bacteriology 64: 679-699. 